\title{
Current and future print storage for Australian academic libraries: Results of a survey
}

\author{
Paul Genoni \\ Curtin University of Technology
}

\begin{abstract}
This paper reports on the results of a 2007 survey of Australian academic libraries and their practice with regard to the storage and disposal of legacy print material. The survey was undertaken in the wake of similar surveys in the United States and the United Kingdom, and with a view to assessing the likely future demand for storage space. The discussion focuses on the advantages of a national print repository based on ceded ownership.
\end{abstract}

Keywords: Academic libraries; Storage; Disposal; Weeding; Australia; Legacy collections; Print repositories

\section{Introduction}

Despite the widespread adoption of digital content many academic libraries suffer from a shortage of space for the storage of print material. Not only do libraries continue to acquire print items, but they also face increasing need to use prime library space for purposes other than storage. In particular, the demand for collaborative learning activities and the associated networked technologies requires space that might otherwise be available for print storage.

At the same time that libraries experience pressure on existing space they are also encountering strong institutional reluctance to alleviate the problem by providing new or extended buildings. Many universities face severe shortages of land; the capital required to fund such buildings has grown substantially, and there is a belief amongst managers that the uptake of digital content should have reduced the need for additional space.

In these circumstances many libraries are turning to off-site storage as a solution. The advantages of off-site storage are found in the reduced cost of land, building and maintenance, which coupled with the cost-effectiveness of high-density storage, can substantially reduce long-term costs. The disadvantages lie in the inevitability of reduced access to stored material, resulting in a further reduction in the use of items that are often stored on the basis of their already low use $\left[{ }^{1}\right]$. Nevertheless, remote storage has a long history of use by research libraries $\left[{ }^{2}\right]$, and evidence indicates that this has increased in recent years and is likely to expand further as improved technologies for storage, discovery and delivery further reduce costs while alleviating some access problems $\left[{ }^{3}\right]$.

An important development has been in the scale of storage facilities. Libraries are realising that developing "industrial-scale" facilities increases cost-effectiveness, and that this can be best achieved by two or more libraries cooperating $\left[{ }^{4}\right]$. While several models exist for the management and operation of cooperative storage facilities, they have in common a desire to take advantage of the economies of scale that result from sharing the cost and use of physical and service infrastructure.

This article reports the results of a survey reviewing the current print storage policies and practices of Australian academic libraries as the basis for anticipating future developments. In particular it is concerned with estimating the extent of any storage "crisis", and assessing the demand for remote storage facilities, be they independent or shared. 


\section{Recent surveys of research library storage}

The interest in print storage has been evidenced by recent surveys and reviews conducted in the United States and the United Kingdom.

The Association of Research Libraries (ARL) has undertaken research in the US in 2006 $\left[{ }^{5}\right]$, with a view to reporting on the evolving space utilisation by member institutions. The data collected in the survey supplements that gathered in similar surveys conducted under the auspices of the ARL in $1977\left[^{6}\right], 1990\left[^{7}\right]$, and $1998\left[^{8}\right]$. The results of these four surveys describe the growing dependence by ARL libraries on remote storage, and the increased use of shared storage facilities.

The 2006 survey received responses from 85 libraries, a response rate of $69 \%$. Of these, 68 (80\%) either had current use of a remote storage facility or were planning to implement such a facility. Twenty-five of these libraries reported that their facility had been operational for less than six years, and 18 were using two or more remote facilities.

Twenty-three (37\%) of the responding libraries indicated that they were using a shared facility, with 18 such shared facilities being reported. This was a considerable increase over the eleven libraries (19\%) that reported having shared facilities in 1998. The shared facilities were reported as being operated either by individual libraries on behalf of partner libraries; by a consortium; by a library system, or by commercial firms providing document storage services.

The report noted that, consistent with conclusions reached by other observers $\left[{ }^{9}\right]$, US research libraries were increasingly relying upon remote and cooperative storage as a means of addressing space shortages.

ARL member libraries' use of remote shelving facilities as a response to space needs has increased since 1998 and, judging from the responses to this survey, this trend will continue. Another upward trend is the use of shared facilities ... [ $\left.{ }^{10}\right]$

In the UK, CHEMS Consulting undertook a similar survey in 2005 on behalf of the Consortium of Research Libraries in the British Isles (CURL) and the British Library $\left[{ }^{11}\right]$. The respondents consisted of 38 higher education libraries and four large municipal libraries, representing $88 \%$ of the libraries surveyed. Of the respondents, $90 \%$ reported that space shortage was a "high priority". It was reported that many of the libraries were reviewing their current disposal policies, and that space shortages were driving libraries towards a more liberal view of disposal. It was also noted that some libraries had adopted a policy of "zero net collections growth".

Some $50 \%$ of responding libraries reported that "they had reached or would shortly reach capacity as regards storage" $\left[{ }^{12}\right]$, and 28 of the libraries were acquiring, or planning to acquire, new space for storage. The survey results indicated that for nineteen libraries that were able to provide data, the shortage of shelving in 2005 amounted to $40 \mathrm{~km}$, with a projected increase to $155.5 \mathrm{~km}$ by 2010, and $270.5 \mathrm{~km}$ by 2015 .

CHEMS Consulting recommended the development of a collaborative storage strategy, the "National Research Reserve", to be based on the existing lending collections of the British Library. Participating libraries are able to free up shelving space by depositing uniquely held titles with the Reserve; and de-duplicate with confidence, safe in the knowledge that items could be borrowed as required.

It should be noted that European countries have led the way with the implementation of national print repositories. The National Repository Library of Finland was founded in 1989, providing cost-effective permanent storage for all Finnish libraries with ownership of stored items being transferred to the Repository. The availability of the Repository has reduced the 
need to build new space for collections $\left[{ }^{13}\right]$. Similar national repositories have been operating since the 1990s in Norway $\left[{ }^{14}\right]$ and France $\left[{ }^{15}\right]$.

\section{Existing Australian cooperative stores}

Australian universities currently have two major cooperative facilities for storing print research materials. The first of these is the Universities Research Repository South Australia (URRSA). Operating since 1984 and with a capacity of 1.35 million volumes URRSA provides for the storage needs of the University of Adelaide, Flinders University and the University of South Australia. Ownership of stored material remains with the depositing library.

The second facility is the CARM Centre managed by CAVAL Collaborative Solutions, and located in outer Melbourne. The CARM Centre has been operational since 1997, providing storage services to member libraries, which currently consist of seven Victorian academic libraries, with the Universities of New South Wales, Western Sydney and Tasmania joining recently $\left[{ }^{16}\right]$. CARM has a capacity of approximately 1 million volumes with planning underway to double this size. Member libraries may cede ownership of material to the CARM collection or they may lease space for storage of their own material. The CHEMS Consulting report noted that the CARM store is "One of the most successful collaborative stores" $\left[{ }^{17}\right]$.

These two existing stores have developed as regional services centred on Adelaide and Melbourne, and libraries outside of these cities have largely relied upon developing independent solutions to their storage needs. There has been discussion within the Council of Australian University Librarians (CAUL) for many years about the possibility of implementing either a national storage facility or an expanded network of regional stores, but to date no such outcomes have eventuated $\left[{ }^{18}\right]$.

\section{Disposal by Australian academic libraries, 1996-2006}

The rates of acquisition and disposal by Australian academic libraries are recorded in the annual statistics gathered by CAUL. The figures reported below are for the acquisition and disposal of non-periodical volumes only. The CAUL statistics do not record the number of periodical volumes disposed. 


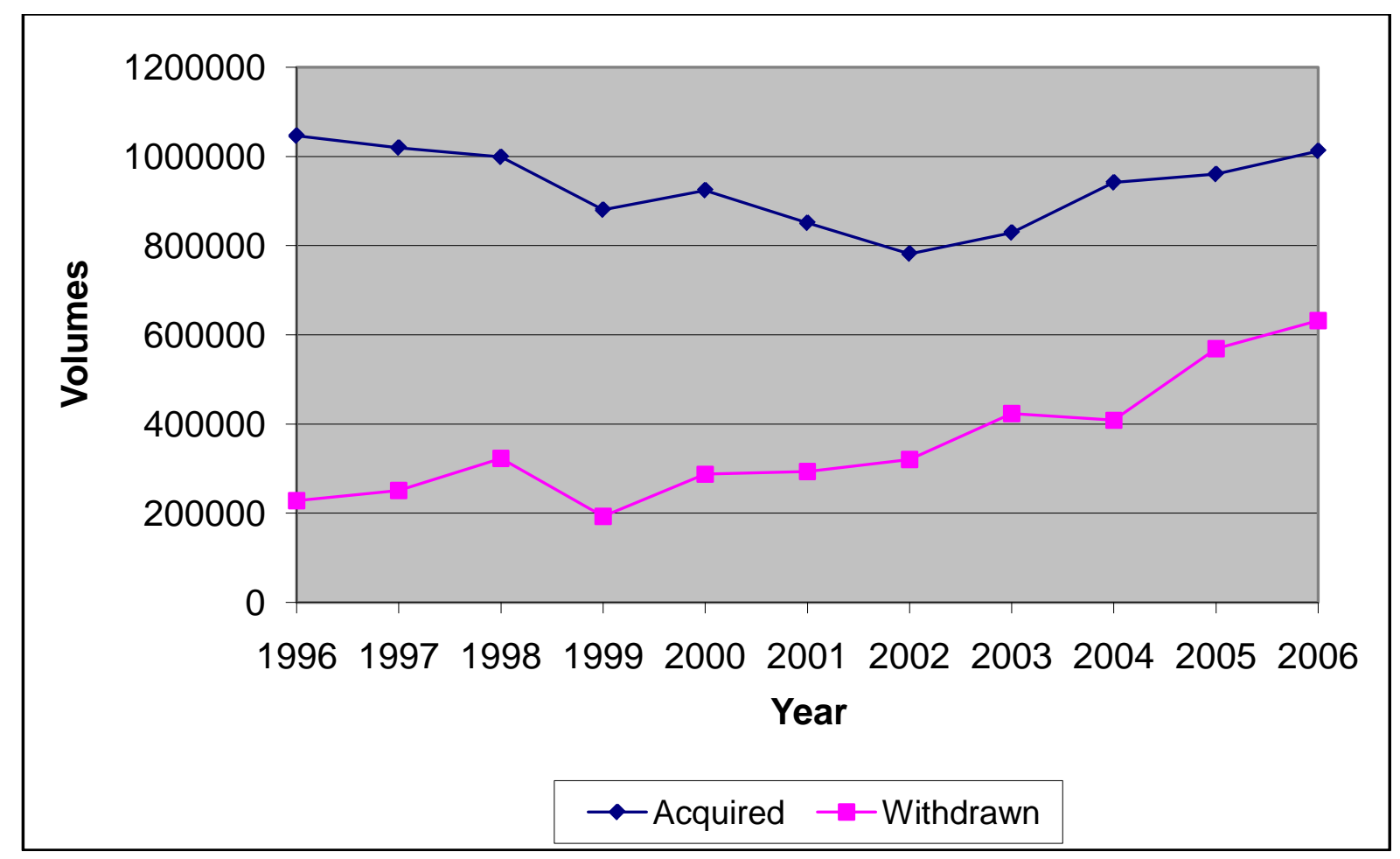

Fig. 1. Non-serial volumes added and withdrawn by CAUL libraries

As indicated in Fig. 1 the rate of acquisition (measured in total number of volumes acquired) declined from 1996-2002, followed by a period of recovery from 2003-2005. The period of decline can be attributed to the impact of the "scholarly publishing crisis", with libraries reducing monograph acquisitions in order to maintain periodical subscriptions in the face of rapidly rising prices. The impact of this crisis was exacerbated in Australia by a significant decline in the value of the Australian currency during this period. As major importers of scholarly publishing Australian libraries faced a severe erosion of their purchasing capacity. The post-2002 recovery reflects the implementation of access to largescale databases of full-text periodicals that has allowed libraries to stabilise their periodical content and refocus attention on non-periodical holdings, coupled with a gradual and ongoing recovery in the value of the Australian dollar. It should be noted, however, that the acquisitions in 2006 (1,012,307 volumes) had still not recovered the 1996 high point of $1,046,378$ volumes.

During this same period the rate of disposal (Fig. 1) displayed an upward trend, capped by a sharply upward movement in 2005 and 2006. The low point for disposals was 1999 (192,957 volumes), which contrasts with the 2006 figure of 631,877—an increase of $227 \%$ in seven years.

Another way of looking at these figures is to graph the annual net gain in volumes held by the CAUL libraries for the same period (Fig. 2). These figures record a declining trend in the net growth of collections over this decade that was only significantly reversed in one year, 2004. The high point for net gain was 1996 (818,042 volumes), and the low point 2006 (380,430 volumes). 


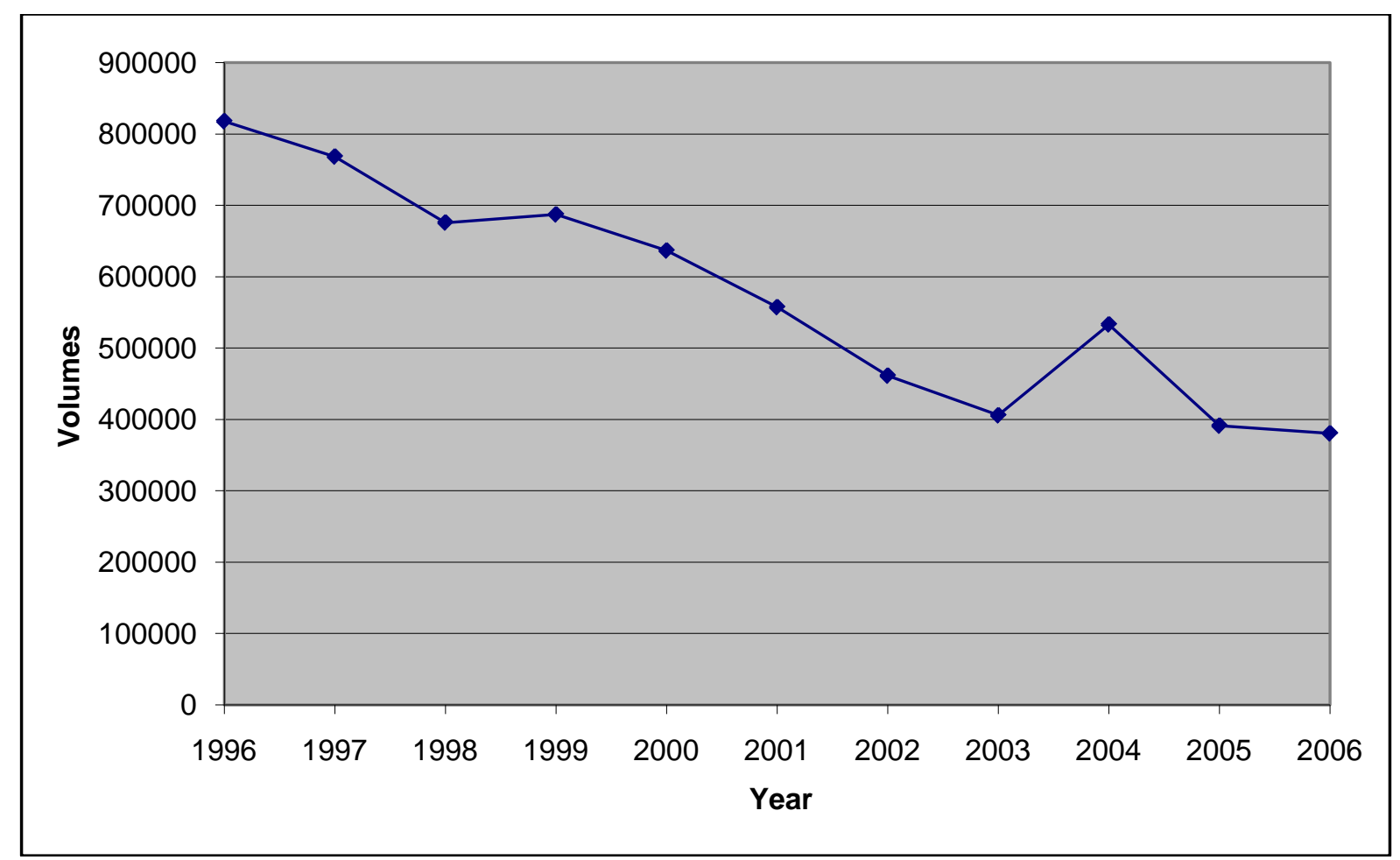

Fig. 2. Net gain in non-serial volumes by CAUL libraries

It is clear that if this rate of decline in the annual net gain continues for another decade, Australia's academic libraries will have collectively reached an effective steady state collection for non-serial holdings. While such an outcome might "solve" the storage problem, it would be of questionable benefit in terms of building the nation's research infrastructure.

An interpretation of the figures reported in Figs. 1 and 2 is that they indicate a group of libraries increasingly relying upon disposal in order to address the problem of limited storage. There are of course various reasons why libraries might dispose of items, but it is frequently an indicator - particularly for research libraries - of storage levels being at or near capacity.

With this in mind it was decided to undertake a survey of the storage and disposal policies and practices of the CAUL libraries, in order to collect data similar to that gathered by the US and UK surveys. This data is critical to determining the types of storage solutions that will meet the needs of both libraries and users of legacy print collections.

\section{The survey}

The survey was distributed to all 40 CAUL libraries in March 2007. It consisted of 18 closed, open and multiple-choice questions. Surveys were returned from 30 (75\%) of the recipients.

\subsection{Existing storage and disposal policies}

Survey respondents were asked to indicate if "your library (has) a written policy and/or procedure regarding the storage and/or disposal of print material?” Twenty-three (76.6\%) reported having such a policy, and seven do not, with one of these seven indicating they are currently developing a policy. All of those libraries without a current policy serve the newer and smaller universities.

Respondents who reported having a policy were asked if it is publicly available. Nine reported that their policy is publicly available, and thirteen that it is not. All of the 23 libraries 
were requested to provide a copy of their relevant policy documents, and copies were obtained from 19. These were then read and assessed for details relating to their content and scope of coverage.

There is a considerable variation in the policy statements. Some have stand-alone documents on disposal and/or storage, while others are integrated into a larger collection management policy document. Some of the policies cover only journals or only monographs, while others deal with both categories.

One matter that is common to many of the policies is the issue of why relegation-for the purpose of either storage or disposal-is required. In a number this comes in the form of a brief statement focussed on the nature of the material that will be removed:

De-selection (or weeding) is an ongoing process carried out to remove obsolete and superseded material from the collection.

In other policies the focus is on the benefits that will result:

(Disposal is) necessary to maintain a relevant and high-quality collection.

The relegation and disposal of books and other material in any large academic library are essential to prevent overcrowding, and to maintain the effectiveness of library services and the quality of library collections.

It is notable, however, that a number of the libraries use their policies to make it clear that extensive weeding is not an action that would be undertaken if sufficient storage space were available in their primary site. A number of the larger libraries use their policy to record their ambitions to build research collections intended for permanent retention on open access, while noting that lack of space prevents them from achieving this goal.

As a library serving a research institution all items in the collection may have some value to our clients in the future and this can be difficult to anticipate . . . (However) the library must confront the problem of accommodating tens of thousands of extra volumes acquired each year.

The Library . . . adds material to its collection on the basis that this material is intended to be kept permanently. It also recognises that to maximise access, wherever possible, its collections should be on open access. However, there is a finite amount of space in each branch library. A similar amount of material must therefore be relocated to alternative storage to retain a net balance.

The ... Library will provide information resources and services to support the (University's) goal of achieving excellence and international recognition as a University of outstanding quality in teaching, research and the educational experience . . . Because the size of the Library's collection has outgrown the space available within the existing buildings . . . we must remove a significant number of volumes to make room for new acquisitions.

The . . . Library has been, for over 25 years, and must continue to be, a steady state library on this site whether we want to or not.

In a similar vein, policies from libraries of some smaller universities acknowledge that with current space limitations they cannot aspire to build major research collections.

The Library is not funded to offer unlimited space for 'just in case' material'.

With little chance of major extensions (the Library) has been, and will continue to be, a steadystate library with a focus on access rather than the maintenance of a print archive.

The survey asked respondents to indicate if their library had "a target figure for print volumes to be stored or disposed in each year or in coming years?” Ten libraries reported 
having such a target, and 19 do not. The libraries that reported having a target were asked to provide details, with seven reporting they were attempting to maintain some form of "steady state" collection. For example:

Target for storage varies from year to year depending on Library resources available, however the aim has been to keep a steady state collection size over an average of 3-5 years.

We attempt to maintain a 'steady state'.

In several cases, specific targets for the reductions required in terms of volumes or shelf space underpinned the goal of a steady state collection.

\begin{abstract}
In general we aim to maintain a steady state collection size. The library has had specific targetsto reduce the size of the periodicals collection from 3020 linear metres to 1900 linear metres-as part of a ... reduction of the footprint of the periodicals collection by approximately $50 \%$.
\end{abstract}

Most branches maintaining a steady state collection size. We estimate approx 535,000 (volumes discarded) by the end of 2016.

Steady state collection which implies the removal of 50,000 volumes per year.

Those respondents who provided specific targets were generally from the largest of the libraries, and the projected figures for withdrawal were considerable. In addition to the figures included in the two examples immediately above (which by extrapolation amount to 1.03 million volumes by 2016), additional estimates included 135,000 volumes for immediate withdrawal, and 620,000 volumes for the three years 2007-2009.

While collection growth undoubtedly drives these disposal targets, a number of respondents also indicated that meeting demand for new teaching and learning spaces was forcing reductions in shelving.

The development of a 'learning hub' at our main campus, open access computer facility, was the main driver for this target, which was achieved in 2006.

Eleven sites maintain a steady state collection. Twelfth site, significant reduction in on-site print resources and increased access to electronic resources planned for learning commons expected in 2009.

Intend to reclaim about 3,500 metres for learning and research support services provided by the library.

It is also worth noting that one of the policies claims that libraries are experiencing a generational change in their users, as the result of which students (conditioned by a life-long exposure to digital content) no longer expect to find a research collection on the shelves.

... the present generation of students does not want to wade through shelves of dated material—a

slimmed-down, relevant collection will encourage use of library materials.

In other words, the library is treating the current student generation as the first "just-in-time" natives.

\title{
5.2. Criteria for storage and disposal
}

The policy statements invariably include a guide to the criteria that will be used to select items for storage or disposal. A number of the policies establish a set of general principles that will be used when selecting material for withdrawal, while others detail separate criteria 
to be applied to monographs and journals. The titles of many of the documents refer to their role as "guidelines" to assist in the identification of material for storage or disposal.

\section{Guidelines for deselection/transfers \\ Guidelines for disposal or archiving of print journal back issues \\ Monograph weeding guidelines \\ Guidelines for withdrawal and relegation of print materials \\ Guidelines for disposal or archiving of print journal back issues}

Given the encompassing nature of the criteria in many of the policies, survey respondents were asked to "specify in order of preference up to three categories of print material you are most likely to permanently discard". Respondents were requested to be as specific as possible, and responses were then grouped accordingly. Table 1 records both the total number of responses given for each criterion, and the number of respondents who listed each criterion as their "first preference" for disposal.

Table 1

Criteria used for disposal

\begin{tabular}{lll} 
Criteria & $n$ & 1st pref \\
\hline Backsets of journals available electronically & 17 & 6 \\
Duplicates of low use monos & 15 & 11 \\
Out of date monos/superseded editions & 13 & 5 \\
Obsolete subjects /curriculum & 7 & 3 \\
Badly damaged items & 7 & 2 \\
Reference sources available online & 6 & 0 \\
Reference sources out-of-date & 4 & 1 \\
Incomplete backsets of journals & 4 & 0 \\
Monographs with no recent borrowing & 3 & 1 \\
Availability of last copy guaranteed & 2 & 0 \\
Duplicated journals within library & 2 & 0 \\
Non-serial items available electronically & 1 & 1 \\
Short serial run, no current subscription & 1 & 0 \\
Newspapers available on microform & 1 & 0 \\
Journals/Newspapers, recent years only kept & 1 & 0 \\
\hline
\end{tabular}

The impact of electronic periodical holdings is apparent, with 17 (56.6\%) of the respondents indicating that they dispose of the backsets of journals that are available electronically. This preference for digital (or other) space saving formats is reflected in a number of the policy documents. For example:

Recent developments in electronic information sources have provided further impetus to relegate to store print books, journal sets, and indexes.

Several libraries stipulated that they would only consider journals for disposal if they had secure access to the backsets of e-journals. This recognition that digital content is often acquired under circumstances that do not guarantee long-term access is also reflected in several policy statements.

Considerations for withdrawal of journals will be impacted by the availability of electronic versions, their archival availability resulting from an existing arrangement, and/or perpetual availability. The source of an electronic title will also impact on withdrawal decisions. Storage options may be preferred to withdrawal in some cases. 
Indeed the result that over $40 \%$ of libraries did not indicate that they would give priority to removing backsets of journals that are available electronically could be seen as an indication of the uncertainty about the security of long-term electronic access. This uncertainty is further reflected in that only six (20\%) libraries nominated this category of material as their first choice for disposal. In comparison 16 (53.3\%) referred specifically to monographs in the category they nominated as their first choice for disposal.

The comparative amount of monograph and journal disposal was explored in a question asking respondents to indicate the number of volumes of monographs; serials and journals; newspapers; and reference material they have "permanently discarded" in the past two years. This was an attempt to assess the extent of all disposals, whereas the CAUL statistics record only the disposal of non-serials.

Unfortunately the results are not conclusive, as some libraries record only those figures required by CAUL. Nine libraries reported disposing of journals but not having recorded the number of volumes. However, of the 20 libraries that provided disposal figures for both monographs and journals, 16 reported having disposed of more monographs than journals over the two-year period. The total monograph volumes reported as having been disposed by these nineteen libraries was 502,033, and the total for journal volumes was 149,353. It should also be noted that whereas four libraries reported they had not disposed of any journals, only one reported not having disposed of any monographs. Despite the missing data it would appear that currently-perhaps contrary to expectations-more monographs are being permanently disposed than journals. The evidence gathered by the survey suggests that libraries are choosing to store backsets of journals and dispose of monographs.

Respondents were asked to report the various disposal methods they had used for print material in the last two years.

Table 2

Method of disposal

\begin{tabular}{lll} 
Method & $n$ & \% (of respondents) \\
\hline Destroyed or sent to waste & 28 & 96.5 \\
Given to another library overseas & 13 & 44.8 \\
Given to another library in Australia & 10 & 34.5 \\
Ceded to repository collection (eg CARM) & 5 & 17.2 \\
Given to charity for sale & 4 & 13.8 \\
Given to student/alumni association for sale & 2 & 6.9 \\
Given/sold to staff/students of the university & 2 & 6.9 \\
Given to international aid organisation & 1 & 3.4 \\
\hline
\end{tabular}

1 response missing

Almost all of the respondents ( $n=28,96.5 \%)$ indicated that had destroyed volumes, so it is likely that this is the fate of much of the discarded material. It is the case, however, that at least some of the material remains available to the Australian library sector, with libraries either donating items to an Australian library $(n=10,34.5 \%)$, or ceding ownership to a cooperative store $(n=5,17.2 \%)$. The sole beneficiary of the ceded volumes was the CARM repository.

\subsection{Last copy disposal}

It is apparent that the disposal of a substantial number of volumes is a common response to space shortages. The impact this might have on the national research collection is to some extent determined by exactly which items are disposed. On the basis of the survey it is not 
possible to identify if unique titles have been disposed, although a number of the policies of responding libraries indicated that attention is given to identifying last copies.

There is some inconsistency, however, in describing exactly what is meant by "last copy". Some libraries interpret this as being a copy within their own library or library system.

The library retains access to at least one copy of all items catalogued into its collection, including all versions and editions. This access shall comprise retention of:

- a print copy on the open shelves in any branch library, or,

- a print copy in storage ... where (the library) retains full ownership, or,

- a print copy in shared ownership in the CARM Centre.

Other libraries undertake their last copy considerations on a regional (state) basis ("consideration will be given to whether other copies of the work are available in the state"), and for yet others last copy status is assessed nationally, with the intention of ensuring that at least one copy remains in an Australian library.

It is imperative that reasonable checks be made to ensure that the last national copy of any academic monograph is not discarded.

In several cases, however, policies have no requirement to ensure that an item destined for disposal is held elsewhere in the state or country, thereby implicitly at least allowing the disposal of a last copy.

\subsection{Current and future space needs}

Respondents were also asked to estimate the current availability of storage space in their primary library site. The information was requested as a percentage, and the survey provided options ranging from "less than 2\%" to "more than 10\%", and "Figure not available".

Table 3

Amount of space available in primary library site

\begin{tabular}{lll} 
Amount & $n$ & $\%$ \\
\hline Less than $\% \%$ & 9 & 33.3 \\
$2-5 \%$ & 6 & 22.2 \\
$5-10 \%$ & 3 & 11.1 \\
More than 10\% & 3 & 11.1 \\
Figure not available & 6 & 22.2 \\
\hline
\end{tabular}

3 responses missing

A calculation, derived from the work of Metcalf $\left[{ }^{19}\right]$ and which has been circulating in library planning literature for some years, concludes that to optimise efficiency a collection should occupy no more than $86 \%$ of available space. The Council of Australian State Libraries (CASL) Working Group on Stack Management has supported this figure recently. The working group also suggested a "vacancy rate of between $25 \%$ and $34 \%$ if constant book moving is to be avoided" $\left[{ }^{20}\right]$. By this measure at least 18 (85.7\%) of the 21 responding libraries substantially exceed the point of being "full".

Evidence of the stress created by operating in excess of capacity is provided by one library that, despite having a comparatively spacious " $5-10 \%$ ” of storage space available, reported:

We are always looking for ways to decrease the amount of print material within the Library but at the moment it is an ongoing battle just to create enough space to place our new print materials on the shelves. To actually get to a point where we are ahead of that need is our long-term goal. 
A further question asked respondents to report if their forward planning indicated a likely increase or decrease in the amount of "space allocated to shelving for print material in your primary library site(s) in coming years". The survey also offered "No opinion" as a possible response.

Table 4

Anticipated future space requirement for print storage

\begin{tabular}{lll} 
& $n$ & $\%$ \\
\hline Decrease & 9 & 33.3 \\
Increase & 9 & 33.3 \\
No opinion & 9 & 33.3 \\
\hline
\end{tabular}

3 responses missing

The nine libraries that reported having 'no opinion' on this matter were generally smaller libraries and included none of the largest research libraries (the so called 'G8'). Five of these nine libraries had been amongst the seven who had reported not having a written collection development policy. These libraries are also amongst the most recent to attain university status and would seem to be yet to attain the level of collection planning enjoyed by their more established counterparts.

Respondents were invited to supply additional information in response to this question. Three of the five who provided added information were from the G8, and they reported very consistent estimates of the likely reduction. One reported that they foresaw a "probably $30 \%$ reduction over 5 years"; another that they had a "proposed project to withdraw or relegate $30 \%$ of print books and journals"; and a third foresaw a reduction from 27,438 shelves to 19,052 shelves (i.e. 30.5\%). On this evidence it appears the deepest cuts to print storage will come from the largest research collections.

Such reductions are not, however, universally anticipated, with eight respondents anticipating an increase in print storage space. Just as revealing is that nine respondents indicated they had "no opinion", providing further evidence of uncertainty regarding the future of print storage and suggesting that a number of libraries are taking a "wait and see" approach with regard to the impact of digital content.

\subsection{Storage facilities}

Of the responding libraries 20 (66.6\%) indicated that they have access to a storage facility, and ten do not. By far the most common form of storage is the autonomously managed local store, with 14 libraries indicating they currently have such a facility. These vary considerably in accessibility. Eight libraries have areas within the main library (including basement and roof spaces) that are designated for storage, with a number using compactus shelving. Other libraries manage a remote store, with distances varying from "on campus" and "within walking distance", to "seven kilometres" and "an hours drive". In all, the 14 respondents with independent storage reported a total of 19 different sites, with one library reporting four sites.

The sizes of the independent facilities also vary considerably. Although detail of volume capacity was requested it would appear that in some cases this calculation is not available. At least four of the libraries, however, reported having a storage capacity in excess of 200,000 volumes, of which one is reported as being in the range of "300,000-500,000 volumes", and another has over 500,000 volumes currently in storage.

Seven of the responding libraries reported having access to the shared storage facility provided by the CARM Centre. As at March 2007 nine academic libraries (seven from Victoria and two from New South Wales) had a total of 438,098 volumes stored with CARM. There is evidence from the survey, however, that the demand from non-Victorian libraries for 
access to the CARM Centre is increasing. The University of New South Wales reported they will surrender a store they are currently "sub-leasing" and "will send some material to CARM in Melbourne and dispose of other material"; and the University of Western Sydney Library noted that they "recently joined CAVAL and have access to the CARM storage facility". The University of Tasmania Library reported that, "We are proposing to join CAVAL and use the CARM store for print journal volumes" (they have subsequently become a member).

A further indication of the interest in shared storage sites came from the University of Sydney, which despite having access to their own substantial store which still has "about two thirds available for future storage", are in the process of "Establishing (a) joint store with Australian National University". The University of Sydney section of the store will be "capable of storing up to 200,000 volumes".

Of the three libraries sharing access to the URRSA facility, only the University of Adelaide responded to the survey. Their response indicated a high level of satisfaction with the URRSA, highlighting the environmental and service benefits that flow from having a purpose built, shared facility.

The University of Adelaide Library has utilised storage for about 25 years. . . . We now have same day (or less than 24 hours) paging in most cases and rarely receive complaints. It is a safe, climatically friendly, convenient option as a destination for many titles. It is part of our normal library operations and a team for removal to storage and withdrawal is now part of the staff structure.

\section{Discussion and conclusion}

From the disposal figures included in the annual CAUL statistics and the survey reported above, it is apparent that Australian academic libraries are currently facing a severe shortage of storage space for print collections in their primary sites. This problem appears to be most acute for the larger libraries with established research collections, but it is clear that many libraries are experiencing the problem. It is also the case that a number of local stores managed by these libraries are experiencing space shortages, and-as evidenced by the CAUL figures - this suggests that the rate of disposal is likely to continue to increase.

There are also indications that, despite the current space shortages, many libraries are uncertain in their planning for future print storage. This is indicated by both the number of libraries reporting they have no data available regarding current spare capacity $(n=6,16.3 \%)$, and the number $(n=9,33.3 \%)$ that are uncertain as to whether they are anticipating an increase or decrease in storage space in their primary site. In response to a further question asking for the number of years over which space planning extended, 13 (43.3\%) did not respond, likely indicating the planning is being done on an ad hoc basis. There are also indications that libraries are unsure as to how to prioritise material for storage or disposal, with ambivalence regarding the need to continue to hold print copies of journals that are available electronically.

In these circumstances libraries are managing the problem by depending on storage, and increasingly disposal, in order to gain space in their primary sites. For many libraries this storage space is still autonomously managed and local, although Victoria and South Australia provide models of successful cooperative storage. There are also indications that libraries from other states are increasingly looking to cooperative storage as a solution to their needs, and that some are prepared to store material at a considerable distance (ie the New South Wales and Tasmanian libraries that have recently taken membership with the Victorian based CARM Centre).

If cooperative storage does become a preferred solution Australian academic libraries will face a critical issue - the extent to which they are prepared to cede ownership of deposited 
items. As libraries come to terms with their incapacity to store low use print collections in either a primary library site or a local store, they increasingly need to consider remote, cooperative storage solutions. The next decision point will be whether they insist on retaining ownership, or if they are prepared to cede ownership to a collaboratively or independently owned and managed facility. While retaining ownership has attractions in terms of maintaining individual collection sizes, ceding ownership can provide substantial savings to the system as a whole, with its capacity to achieve higher shelving densities; to encourage far greater de-duplication; and to optimise efficiency in the discovery and delivery of stored items. In the UK the ceding of ownership to the National Research Reserve has been critical to the national storage plan, where it is seen as critical in achieving substantial reductions of locally held stock while retaining security of access. As reported in the survey, only five of the responding Australian libraries have ceded ownership of items in the last two years, all to the CARM Centre. Several member libraries have also leased space within the CARM Centre for storage of material, but they have stopped short of ceding the ownership of this material.

Australian academic (and other research libraries) would also benefit by resolving two other issues. The first is the definition and status of last copies. As indicated above there is no current agreement on what constitutes a last copy, or indeed as to whether a single copy remaining within Australian research libraries is adequate. The second, related matter is the comparative priority to be given to monographs and periodicals, and in particular the need to reach agreement on the desirability of securing a last print copy of periodicals available from a secure source (for example J-Stor). Both of these issues have been discussed within CAUL without resolution. Future decisions regarding cooperative storage would benefit from agreement on these issues reached by CAUL in consultation with non-academic research libraries.

From their survey and interviews undertaken in the UK in 2005, CHEMS Consulting concluded that:

. . . the present arrangements for storage and disposal cannot guarantee two key essentials in a national strategy for research materials: that a small number of copies . . . of all items should be preserved in perpetuity, and that at least one copy should be accessible to researchers. $\left.{ }^{21}\right]$

While the UK has taken steps to address these issues, no similar response has been forthcoming in Australia. In circumstances where substantial storage and disposal are increasingly the preferred methods for handling space shortages, the onus is on Australian academic libraries to take a planned and collective approach that maximises the efficiency of storage, discovery and delivery, while minimising the danger of losing last copies from the national research collection.

The UK response - to devise and implement a "national strategy for research materials" can also bring great benefits to Australia's research infrastructure. The solutions implemented by such a national strategy would likely have elements in common with that adopted in the UK. That is, a national research collection, built on ceded ownership and guaranteeing secure storage and supply within the network, thereby allowing libraries to optimise space by confidently disposing of duplicated low use print material. The alternative is to persevere with the current undesirable situation whereby many of the nation's major research libraries are drifting towards their own versions of a "steady state" collection.

One element an Australian national storage strategy for research materials won't have in common with the UK solution is the emphasis on the central role of a national library. The National Library of Australia (NLA) does not have the breadth or depth within its collections to perform the same pivotal function played by the British Library. Some coordination between the CAUL libraries and the NLA would, however, be desirable and necessary if the potential benefits of a national strategy are to be optimised. The NLA's role as a deposit 
library for Australian publishing and its history of deep collecting of Australiana means that it already has much of this material stored for permanent retention and supported by circulating copies. Any national storage strategy built on the collections of the academic and other research libraries should take account of this and attempt to focus on areas of collecting that are complementary to those of the NLA.

Australia is, however, fortunate in having in place some of the preconditions that would ease the implementation of a national collaborative strategy for print storage. These include a near comprehensive national bibliographic database; a fully developed and well-regarded system of interlibrary lending and library cooperation; and the potential backbone of a national print repository in the form of CARM and URRSA. The comparatively small number of major research collections (both university based and non-university based) also makes the task of reaching agreement of the operation and management of a national repository eminently achievable.

In a 2007 report on the future of print storage in North America Lizanne Payne concluded that:

Academic institutions and the libraries that serve them could provide lasting benefits to scholarship and economies to their institutions by proactively developing a collaborative print repository network on a regional, national or global scale. $\left({ }^{22}\right)$

It is likely that the dual benefits highlighted by Payne will provide irresistible momentum in support of the need for broadly based print repositories. The practice of burdening research libraries with the cost of maintaining "just-in-case" access to rarely used and duplicated material is increasingly unsustainable, as is the risky strategy of having high rates of disposal that proceed with little or no coordination. The evidence from the survey reported above indicates that Australian academic libraries are struggling to deal with space and storage problems on a local, or at best, regional scale. It is probable that current strategies are producing short term solutions to space shortages, but it is unlikely to provide the longer-term benefits to researchers or research institutions referred to by Payne. These benefits may only be achieved by a fully coordinated and implemented national storage strategy based on ceded ownership.

\section{Appendix}

The following survey was distributed to all CAUL member libraries in March 2007.

\section{Library name}

2. Does your library have a written policy and/or procedure regarding the storage and/or disposal of print material?

$$
\begin{array}{ll}
\text { Yes } & \text { (Please go to Q. 3) } \\
\text { No } & \text { (Please go to Q. 6) }
\end{array}
$$

3. If you answered 'Yes' to Q 2, is this policy and/or procedure publicly available?

Yes (Please go to Q. 4) 
4. If you answered 'Yes' to Q. 3, could you provide the URL for this policy if it is available on a website? If your policy is not available on a website could you please attach and return a copy with your survey response.

5. If you answered 'No' to Q. 3, but you would be willing to provide a copy of the policy and/or procedure for this purpose of this survey, could you please attach and return a copy with your survey response.

6. Does your library have a target figure for print volumes to be stored/disposed in each year or in coming years? (This may be either a target number of volumes, or a target expressed in terms such as 'maintaining a steady state collection size')

$$
\begin{array}{ll}
\text { Yes } & \text { (Please go to Q. 7) } \\
\text { No } & \text { (Please go to Q. 8) }
\end{array}
$$

7. If you answered 'Yes' to Q. 6, could you please provide details of this target?

8. Does your Library have access to an off-site storage facility for print material?

$$
\begin{array}{ll}
\text { Yes } & \text { (Please go to Q. 9) } \\
\text { No } & \text { (Please go to Q. 10) }
\end{array}
$$

9. If you answered 'Yes' to Q. 8 could you please provide brief details (ie location in relation to library; approximate no of volumes in storage; capacity in terms of volumes; is it shared with another institution?)

10. Has your Library permanently discarded any of the following categories of print material in the past two years? If 'Yes', please provide an estimate of the number of volumes in each category. If this is not possible, an estimate of the total number of volumes discarded would be helpful.

$$
\text { Yes No Approx no of volumes }
$$

Monographs

Serials/ Journals

Newspapers

Reference material 
11. Could you specify in order of preference up to three categories of print material you are most likely to permanently discard. (Be as specific as possible. For example, 'Backsets of serials that are available electronically', rather than just 'Serials')

1.

2.

3.

12. Please indicate if your library has disposed of print material in the past two years using any of the following methods.

Given to another library in Australia

Given to another library overseas

Ceded to repository collection (eg CARM store)

Destroyed or sent to waste

Other (please specify)

13. Please provide an estimate if possible of the available storage space (as a \% of all space) for print material in your primary library site(s).

Less than $2 \%$

$2-5 \%$

$5-10 \%$

More than $10 \%$

Figure not available

14. Does your forward planning include an estimate of a likely increase or decrease in requirement for space allocated to shelving for print material in your primary library site(s) in coming years (for example, next 2-10 years?)

Increase

Decrease

No opinion
(Please go to Q. 15)

(Please go to Q. 15)

(Please go to Q. 16)

15. If you responded 'Increase' or 'Decrease' to Q. 14 could you please provide details (eg. estimated number of volumes added or reduced, or estimated metres of additional shelving added or reduced). 
16. Please add any additional comments you may have regarding your library's likely approach to the storage and/or disposal of print materials in the coming years.

Thank you very much for your assistance with this survey.

\section{References}

[ $\left.{ }^{1}\right] \quad$ Hill, J. B., Madarash-Hill, C., \& Hayes, N. (2000). Remote storage of serials: Its impact on use. Serials Librarian, 39 (1), 29-39.

$\left.{ }^{2}\right] \quad$ Block, D. (2000). Remote storage in research libraries. Library Resources and Technical Services, 44 (4), 184-189.

$\left.{ }^{3}\right]$ Payne, L. (2005). Depositories and repositories: Changing models of library storage in the USA. Library Management, 26 (1/2), 10-17; Reilly, B. F. (2003). Developing print repositories: Models for shared preservation and access. Washington, DC: Council on Library and Information Resources. Retrieved from the World Wide Web: http://www.clir.org/pubs/reports/pub117/pub117.pdf;

[ $\left.{ }^{4}\right] \quad$ Chepesuik, R., \& Weeks, D. (2002). The Harvard Model and the rise of shared storage facilities. Resource Sharing and Information Networks, 16 (2), 159-168.

[5] Deardorff, T. C., \& Aamot, G. J. (2006). Remote shelving services. SPEC Kit 295. Washington, DC: Association of Research Libraries.

$\left.{ }^{6}\right] \quad$ Cornell University Libraries (1978). A survey of compact storage facilities and collections in the member libraries of the Association of Research Libraries (ARL): A preliminary report. SPEC Kit 39. Washington, DC: Systems and Procedures Exchange Center.

$\left.{ }^{7}\right] \quad$ Steel, V. (1990). Remote storage: Facilities, materials selection and user services. SPEC Kit 164. Washington, DC: Association of Research Libraries.

$\left.{ }^{8}\right] \quad$ Merrill-Oldham, J., \& Reed-Scott, J. (1999). Library storage facilities, management, and services. SPEC Kit 242. Washington, DC: Association of Research Libraries.

$\left[{ }^{9}\right] \quad$ Agee, J., \& Naper, S. (2007). Off-site storage: An analysis. Collection Building, 26 (1), 20-25; Pastine, M., Dorian, J., \& Dougherty, A. (1999). Library Issues, 20 (1), 1-4; Seaman, S. (2005). Collaborative collection management in a high-density storage facility. College \& Research Libraries, 66 (1), 20-27.

$\left[{ }^{10}\right] \quad$ Deardorff, T. C., \& Aamot, G. J. (2006), p. 15.

$\left.{ }^{11}\right]$ CHEMS Consulting. (2005). Optimising storage and access in UK research libraries: A study for CURL and the British Library. Retrieved from the World Wide Web: http://www.curl.ac.uk/about/documents/CURL_BLStorageReportFinal-endSept2005.pdf

$\left.{ }^{12}\right]$ Ibid., p. 17.

$\left.{ }^{[13}\right]$ Vattulainen, P. (2004). National repository initiatives in Europe. Library Collections, Acquisitions, \& Technical Services, 28 (2), 39-50.

$\left[{ }^{14}\right] \quad$ Henden, J. (2005). The Norwegian repository library. Library Management, 26 (1/2), 73-78

$\left[{ }^{15}\right]$ Vattulainen, P. (2004).

$\left.{ }^{16}\right]$ O'Connor, S. (2004). Collaborative strategies for low-use research materials. Library Collections, Acquisitions \& Technical Services, 28 (1), 51-57.

$\left[{ }^{17}\right] \quad$ CHEMS Consulting, p. 32.

$\left[{ }^{18}\right]$ Genoni, P. (2007). Towards a national print repository for Australia: Where from and where to? Australian Academic \& Research Libraries, 38 (2), 84-98.

$\left[{ }^{19}\right] \quad$ Metcalf, K. D. (1986). In P. D. Leighton, \& D. C. Weber (Eds.), Planning academic and research library buildings ( $2^{\text {nd }}$ ed.) (pp. 155-156). Chicago: American Library Association.

$\left[{ }^{20}\right] \quad$ Brown, J., Morley, T., \& Salter, L. (2006). Council of Australian State Libraries (CASL) working group on stack management: Guidelines for planning collection storage of physical collections. Library Collections, Acquisitions, \& Technical Services, 30 (1/2), 85-101, p. 88.

$\left[{ }^{21}\right] \quad$ CHEMS Consulting, p. 27. 
${ }^{22}$ ] Payne, L. (2007). Library storage facilities and the future of print collections in North America. Dublin, Oh.: OCLC, p. 26. Retrieved from the World Wide Web.

http://www.oclc.org/programs/publications/reports/2007-01.pdf 